\title{
Factors affecting the vertical distribution of Betula platyphylla var. japonica and Betula ermanii on Mt. Neko in Nagano Prefecture, Japan
}

\author{
Otsubo Jiro ${ }^{1}$, Mariko Shigeru ${ }^{2}$ and Hayashi Ichiroku, ${ }^{3,4}$ \\ ${ }^{1}$ IDEA Consultants, Inc., 2-2-2 Hayabuchi, Tsuzuki, Yokohama, Kanagawa 224-0025, Japan \\ ${ }^{2}$ Institute of Biology, University of Tsukuba, Tennodai, Tsukuba, Ibaraki 305-8577, Japan \\ ${ }^{3}$ Sugadaira Montane Research Center, University of Tsukuba, Sanada, Nagao 386-2204, Japan \\ ${ }^{4}$ Present address: 173-5 Kosato, Ueda, Nagano 386-0005, Japan
}

Betula platyphylla var. japonica and Betula ermanii segregate vertically at an elevation of approximately 1,850 m on Mt. Neko in Nagano Prefecture, Japan. B. platyphylla var. japonica and B. ermanii were the dominant species below and above this altitude, at which the mean-annual and growing-season air temperatures were $4^{\circ} \mathrm{C}$ and $14.1^{\circ} \mathrm{C}$, respectively. Based on a modification of Kira's warmth index which employs cumulative temperature represented as ${ }^{\circ} \mathrm{C}$ day, leaf unfolding in both species was observed to be initiated at $58^{\circ} \mathrm{C}$ day and $169^{\circ} \mathrm{C}$ day, respectively. In 1996 , leaf unfolding was initiated on 18 May in B. platyphylla var. japonica (+/-6 days) and on 5 June in B. ermanii ( $+/-8$ days), shortly after the last frost which occurred on 5 May 1995 above 1,850 m; below this elevation there was no risk of frost at the time. At elevations above $1,850 \mathrm{~m}$, the unfolded leaves of B. platyphylla were damaged by late frost, while B. ermanii escaped injury because the leaves were still protected by winter buds. The optimum temperature for seed germination in both B. platyphylla and B. ermanii was $30^{\circ} \mathrm{C}$. Temperature alternation from 10 to $30^{\circ} \mathrm{C}$ and moist storage of seeds at $4^{\circ} \mathrm{C}$ (stratification) prior to incubation increased germination rates in both species. The seedlings of $B$. ermanii had a greater survival rates than those of $B$. platyphylla var. japonica when planted above 1,850 $\mathrm{m}$. Comparisons of the timing of leaf unfolding and the latest frost at a site appeared to be the main factors affecting the vertical distribution of these species.

Key words: Betula ermanii, Betula platyphylla var. japonica, germination, leaf phenology, vertical distribution

\section{INTRODUCTION}

Studies on the vertical segregation of plants in Japan were initiated by Imanishi (1949) in the North Alps of central Japan. Thereafter, Takahashi (1962) described the vertical distribution of mountain forests in Central Honshu, and more recently Ohsawa (1984) examined the distribution of forest communities at different elevations on Mt. Fuji. These studies mainly focused on the floristic composition and structure of the forests. Betula platyphylla var. japonica (Miq.) Hara and Betula erma- nii Cham. segregate vertically at an elevation of 1,850 m on the southern slope of Mt. Neko in Nagano Prefecture, Japan. The altitudinal change in floristic composition on Mt. Neko was studied first by Tanouchi and Hayashi (1981), but no causative relationship between environmental parameters and the altitudinal distribution of $B$. platyphylla var. japonica and B. ermanii was discussed. We have attempted to clarify the factors affecting the vertical distribution of these species by relating ecological (c) This is an Open Access article distributed under the terms of the Creative Commons Attribution Non-Commercial License (http://creativecommons.org/licenses/by-nc/3.0/) which permits unrestricted non-commercial use, distribution, and reproduction in any medium, provided the original work is properly cited.
Received 6 August 2009, Accepted 29 December 2009

*Corresponding author

E-mail: ihayashi@coral.ocn.ne.jp 
traits such as leaf phenology and seed germination to environmental conditions on the mountain (Kikuzawa 1983, Kudo 1995, Chuine and Beaubien 2001). In this study, those ecological characteristics affecting to the thermal environment of these species were examined through germination, leaf phenology, and the growth of seedlings (Raulier and Bernier 2000)

\section{MATERIALS AND METHODS}

\section{Study area}

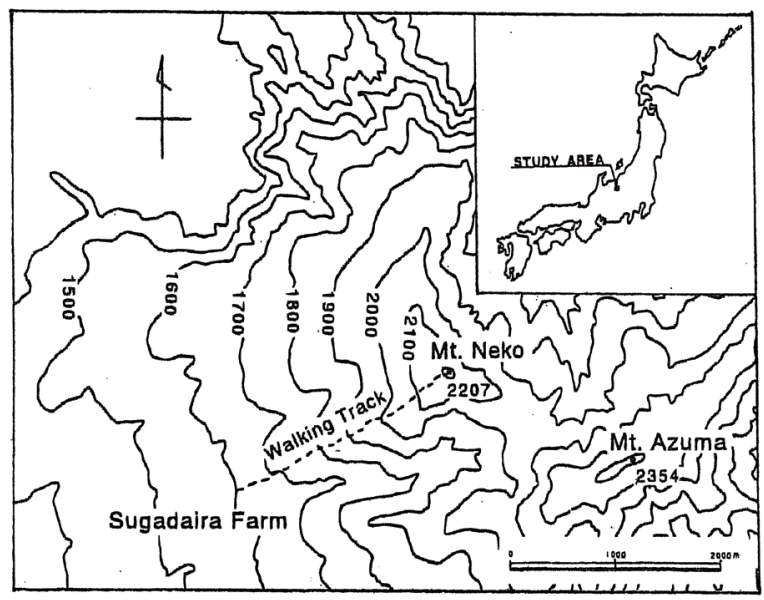

Fig. 1. Location of the study area in Sugadaira, Nagano Prefecture, Japan.

Sugadaira $\left(36^{\circ} 31^{\prime} \mathrm{N}, 138^{\circ} 21^{\prime} \mathrm{E}\right)$, located at an elevation of $1,320 \mathrm{~m}$ (Fig. 1), has a mean annual air temperature and total annual precipitation of $6.5^{\circ} \mathrm{C}$ and $1,102 \mathrm{~mm}$, respectively. The area lies in the cool temperate zone and supports a climax forest of summer-green, broadleaved trees dominated by Fagus crenata Blume. Above around 1,850 $\mathrm{m}$, these species are replaced by evergreen conifers such as Abies veitchii Lindl. Most of the area in Sugadaira is occupied by secondary forest consisting of Quercus crispula Blume, Pinus densiflora Sieb. et Zucc., B. platyphylla var. japonica and B. ermanii interspersed with plantations of Larix leptolepis Sieb. et Zucc. Gordon, farms, ski slopes and cultivated lands (Tanouchi and Hayashi 1981). The soils are Andosols, which have developed on volcanic deposits from Mt. Azuma and Mt. Neko $(2,207 \mathrm{~m})$ slopes gently to the south with steeper slopes on its northern flank, which are associated with the old crater. Distinct forest zones can be observed at different elevations on the mountain, with $P$. densiflora being dominant at 1,300-1,500 m. At 1,500-1,800 m, the forests are mainly composed of B. platyphylla var. japon- ica which is then replaced on the upper slopes by B. ermanii $(1,800-2,100 \mathrm{~m})$. A. veitchii is the dominant species at 2,000-2,100 m. Tanouchi and Hayashi (1981) suggested that this zonation reflected the interaction between the forests and environmental conditions and human activities. The study site was located on the southern slope of Mt. Neko, extending from 1,600 $\mathrm{m}$ to the summit.

\section{Vegetation survey}

Floristic composition, trunk diameter at breast height (DBH) for trees larger than $1 \mathrm{~cm}$ diameter, and tree height was assessed in $10 \times 10 \mathrm{~m}$ quadrats located at elevations of 1,750, 1,800, 1,850, 1,900, 2,000, 2,100, and 2,200 m. Additional quadrats were sampled at $1,845 \mathrm{~m}$ and 1,855 $\mathrm{m}$, in the transitional zone between B. platyphylla var. japonica and B. ermanii. The trunks of both B. platyphylla var. japonica and B. ermanii often sprouted from stem bases, and in this survey, such sprouts were considered to be single trees. Field work was conducted from 8-20 September 1995.

\section{Temperature measurements}

Auto-recording thermometers (Corner System LcII; Corner System Co Ltd. Sapporo, Japan) were used to measure air and soil temperatures. These were placed in an open area on the summit of Mt. Neko (2,200 m) and at elevations of $1,700 \mathrm{~m}$ (mid-elevation of the B. platyphylla var. japonica zone), 1,850 $\mathrm{m}$ (boundary between the $B$. platyphylla var japonica and B. ermanii zones) 1,960 m (mid-elevation of the B. ermanii zone). Above-ground air temperature $(1.3 \mathrm{~m})$ and soil temperature $(10 \mathrm{~cm}$ depth) were recorded at hourly intervals from June 1995 to $\mathrm{Au}$ gust 1997. During the last 10 days of August 1997, soil temperature at a depth $2 \mathrm{~cm}$ was also measured at 1,850 $\mathrm{m}$.

\section{Germination tests}

Germination tests were conducted on B. platyphylla var. japonica and B. ermanii seeds collected at elevations of 1,750 m (28 September 1995) and 2,050 m (18 September 1995). The seeds of both species were incubated under constant temperature conditions at 10, 15, 20,25 , and $30^{\circ} \mathrm{C}$, and under alternating temperature conditions at $10 / 20,15 / 25$, and $10 / 30^{\circ} \mathrm{C}(16$ hours in low temperature, 8 hours in high temperature). Germination was conducted under a 16L:8D regime for 40 days, with the light intensity in the chamber being $80 \mathrm{~mol} \mathrm{~m}^{-2} \mathrm{~s}^{-1}$ for 
the duration of the experiment. Forty seeds were sown in each Petri dish with five replicates performed for both species and seedling emergence was monitored daily. In addition, we examined the germination of seeds which stratified at $4^{\circ} \mathrm{C}$ for 134 days.

\section{Measurement of seedling growth}

Twelve 50-day-old B. platyphylla var. japonica seedlings and four B. ermanii seedlings were planted at uniform distances in a deep plastic pot $(10 \mathrm{~cm} \times \Phi 9 \mathrm{~cm})$ with four replications. A mixture of a typical Andosol and immature soil (Akadama-tsuchi) was used for cultivation. The seedlings were grown under temperature conditions of $10,14,20$, and $30^{\circ} \mathrm{C}$ under constant light $\left(60 \mathrm{~mol} \mathrm{~m}^{-2}\right.$ $\left.\mathrm{s}^{-1}\right)$ for 40 days. Seedlings were harvested on days of 21, 47,67 , and 90 after planting and survival rates were calculated before weighing after drying in an oven for 2 days at $70^{\circ} \mathrm{C}$. In order to assess seedling establishment under field conditions, we transplanted ten 30-day-old seedlings of each species to elevations of 1,600, 1,850, 2,050, and 2,200 $\mathrm{m}$ on 21 July 1997 . The seedlings were planted in unglazed pots $(\$ 14 \mathrm{~cm} \times 14 \mathrm{~cm})$ with the same soil as the that used in the laboratory experiments. We recorded seedling survival for each pot at each altitude on 29 August and 8 October, which were 52 and 92 days after planting, respectively.

\section{Observation of leaf phenology}

Leaf unfolding in B. platyphylla var. japonica and $B$. ermanii trees growing in close proximity was related to a modified Kira's warmth index (WI) (Kojima et al. 2003), which was calculated as the sum of the mean daily temperatures above $5^{\circ} \mathrm{C}$ expressed as ${ }^{\circ} \mathrm{C}$ day. The annual WI was calculated by summing the mean daily temperature from January 1 for each year. The stages of leaf unfolding identified were as follows (Kojima et al. 2003):

L0: winter bud.

L1: a bud swells and its end splits so that green tissues are exposed.

L2: distal end of leaf open and leaf unfolding has begun.

L3: joint of first leaves opens and a clear leaf shape can be identified.

L4: second leaves begin unfolding.

L5: all leaves completely unfolded and maximum leaf area attained.

\section{RESULTS}

\section{Vegetation}

Table 1 shows the floristic composition of selected elevations on Mt. Neko. Species dominance of trees changed from B. platyphylla var. japonica to B. ermanii at 1,850 $\mathrm{m}$. The shrub stratum at higher elevations was comprised mainly of Vaccinium vitis-idaea Linn. and Salix reinii Franch. et Savatit while Rhododendron japonicum (A Gray) Suringer, Sasa senanensis Franchet et Savatier Rehder var. senanensis and Miscanthus sinensis Anderss were common at lower elevations. At higher elevations, Vaccinium uliginosum Linn was abundant in the shrub layer. S. senanensis was the most dominant herbaceous species at all elevations. Except for the tree species, no marked changes in floristic composition were observed at $1,850 \mathrm{~m}$ in the transitional zone between the B. platyphylla var. japonica and B. ermanii communities. The change in the relative frequency of B. platyphylla var. japonica and B. ermanii and the abrupt transition in dominance at 1,850 $\mathrm{m}$ are shown in Fig. 2. From 2,000 to 2,100 $\mathrm{m} B$. ermanii constituted the canopy tree species, but at the summit it grew in association with $A$. veitchii and $A$. mariesii Masters. At around 1,750 m, Salix bakko Kimura and Salix commixta Hedl. appeared in the understory, resulting in a slight decrease in the relative frequency of $B$. platyphylla var. japonica.

The changes in DBH and tree density for B. platyphylla var. japonica and B. ermanii with elevation are shown in Fig. 3. The DBH of most trees ranged between 1 $\mathrm{cm}$ and $12 \mathrm{~cm}$, with the density of B. platyphylla var. japonica decreasing with elevation while that of $B$. ermanii increased. The trees of $B$. platyphylla var. japonica have not distributed in the site above $2,000 \mathrm{~m}$. The change in DBH versus tree height at different elevations for B. ermanii and B. platyphylla var. japonica is presented in Fig.

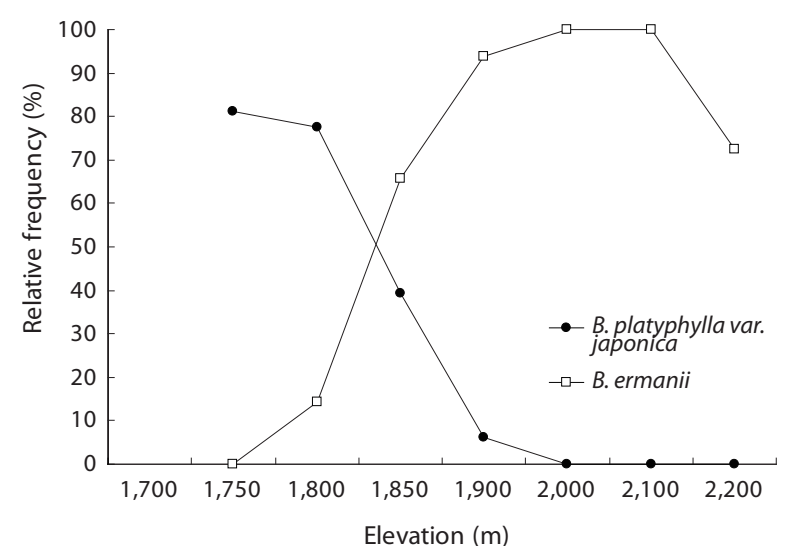

Fig. 2. Relative frequency of Betula ermanii and Betula platyphylla var. japonica at different elevations on Mt. Neko. 
Table 1. Floristic composition of the study sites on Mt. Neko

\begin{tabular}{|c|c|c|c|c|c|c|c|c|c|}
\hline Elevation (m) & 1,750 & 1,800 & 1,845 & 1,850 & 1,855 & 1,900 & 2,000 & 2,100 & 2,200 \\
\hline Tree height (m) & 4-9 & $4-8$ & 4-9 & 4-9 & 4-9 & 4-8 & 4-8 & $>2$ & $>2$ \\
\hline Percent cover $(\%)$ & 70 & 50 & 30 & 50 & 70 & 70 & 50 & 30 & 40 \\
\hline Shrub height (S) (m) & $1-4$ & $1-4$ & $1-4$ & $1-4$ & $1-4$ & $1-4$ & $1-4$ & $1-2$ & $0.5-2$ \\
\hline Percent cover $(\%)$ & 40 & 30 & 40 & 30 & 20 & 15 & 20 & 10 & 100 \\
\hline \multicolumn{10}{|l|}{ Herb (H) } \\
\hline Percent cover $(\%)$ & 90 & 70 & 90 & 80 & 95 & 100 & 100 & 100 & \\
\hline \multicolumn{10}{|l|}{ Coverage of Tree * } \\
\hline Betula ermanii & & 1 & 2 & 3 & 4 & 4 & 3 & 3 & 3 \\
\hline Betula platyphylla var. japonica & 3 & 3 & 2 & & & & & & \\
\hline Abies veitchii & & & & & & + & + & & 1 \\
\hline Abies mariesii & & & & & & & & & 2 \\
\hline Salix bakko & 1 & & & & & & & & \\
\hline \multicolumn{10}{|l|}{ Coverage of shrub layer* } \\
\hline B. ermanii & & + & 2 & 2 & + & 2 & 1 & & \\
\hline B. platyphylla var. japonica & 3 & 2 & 3 & 1 & + & + & & & \\
\hline Sasa senanensis & & & & & & & & & 5 \\
\hline Salix. reinii & 1 & & & + & & & 2 & + & \\
\hline Sorbus commixta & & + & & & & & & + & \\
\hline Vaccinium smallii & & & & + & & & & + & \\
\hline S. bakko & 1 & + & & + & + & & & & \\
\hline Rhododendron japonicum & & + & 1 & & + & & & & \\
\hline Malus sieboldii & & + & & & & & & & \\
\hline \multicolumn{10}{|l|}{ Coverage of herb layer* } \\
\hline S. senanensis & 4 & 4 & 5 & 4 & 5 & 5 & 5 & 4 & \\
\hline R. japonicum & 2 & 1 & 1 & 1 & 1 & 1 & + & + & \\
\hline S. reinii & 1 & & 1 & & & & + & 3 & \\
\hline Pyrola incarnata & & + & + & & & & 1 & 1 & \\
\hline Vaccinium uliginosum & & & & & & & + & 1 & \\
\hline Vaccinium vitis-idaea & & & & & & & + & 1 & \\
\hline Shortia soldanelloides & & & & & & + & + & 1 & \\
\hline Ixeris dentata & & & & & & & & + & \\
\hline Coptis trifoliolata & & & & & & & & + & \\
\hline Solidago virga-aurea var. asiatica & & & & & & & & + & \\
\hline Maianthemum dilataum & & & & & & & & + & \\
\hline Lastrea phegopteris & & & & & & & & + & \\
\hline Calamagrostis langsdorffii & & & & & & & & + & \\
\hline Convallaria keiskei & & & & & & & & + & \\
\hline B. ermanii & & & & & & & & + & \\
\hline V. smallii & & & & & & & & + & \\
\hline Scabiosa japonica & & & & & & & + & + & \\
\hline Prunus nipponica & & & & & & & + & + & \\
\hline Astilbe thunbergii & & & & & & & + & + & \\
\hline Gentiana triflora & & & & & & & + & + & \\
\hline Gentiana scabra & & + & & & & & + & + & \\
\hline Osmunda lancea & & + & + & & & & & + & \\
\hline Gaultheria miqueliana & & & 1 & 1 & & & + & + & \\
\hline S. commixta & & & & & & & + & & \\
\hline Rosa davurica & & & & & & & + & & \\
\hline Polygonum cuspidatum & & & + & + & + & & & & \\
\hline Pteridium aquilinum & 1 & + & 2 & + & + & & & & \\
\hline Athyrium yokoscense & & + & + & & & + & + & & \\
\hline Carex chinoi & & + & & & + & + & & & \\
\hline Betula platyphylla var. japonica & & & & & + & & & & \\
\hline Carex lanceolata & & & + & & & & & & \\
\hline Miscanthus sinensis & + & + & 1 & & & & & & \\
\hline
\end{tabular}

* Criteria of coverage is Penfound-Howard modified by Numata (1986). 
a

B. platyphylla var. japonica

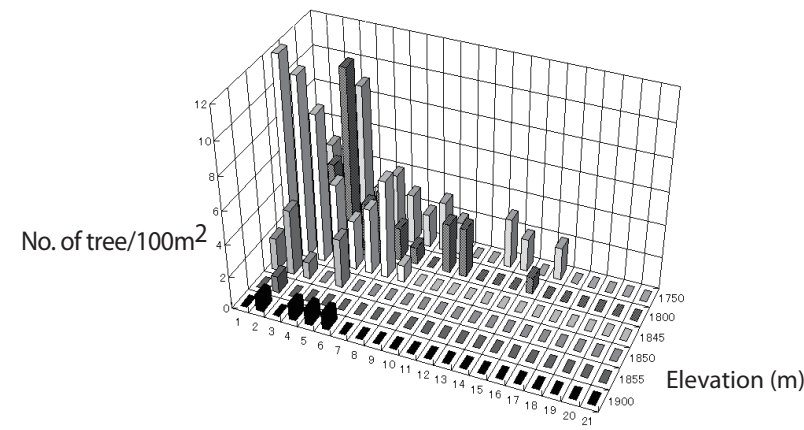

$\mathrm{DBH}(\mathrm{cm})$

(b) B. ermanii

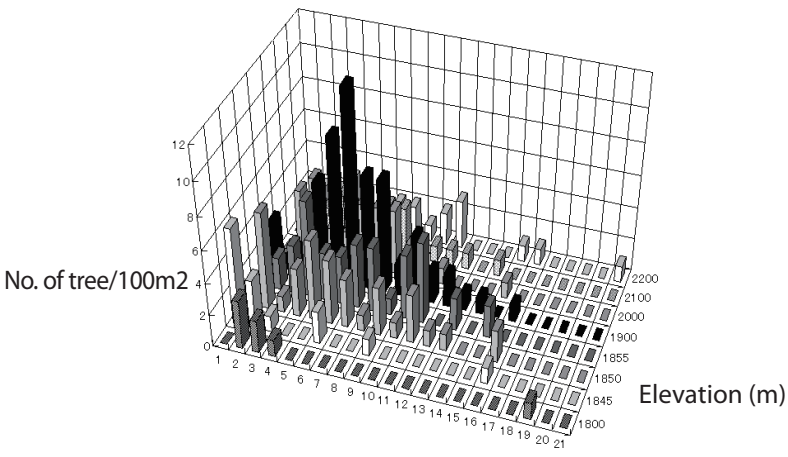

$\mathrm{DBH}(\mathrm{cm})$

Fig. 3. Relationships between diameter at breast height (DBH) and elevation in Mt. Neko for Betula ermanii (a) and Betula platyphylla var. japonic (b)

4. The ratio of tree height to DBH was more variable in $B$. ermanii than B. platyphylla var. japonica, particularly for larger trees. Thus, B. ermanii trees with DBHs exceeding $12 \mathrm{~cm}$ ranged between about $4 \mathrm{~m}$ to $9.5 \mathrm{~m}$ in tree height compared to about $7 \mathrm{~m}$ to $9.5 \mathrm{~m}$ for B. platyphylla var. japonica. The plasticity in tree growth form of B. ermanii was greater than that of B. platyphylla var. japonica. At the elevation above $2,100 \mathrm{~m}$, the ratio of tree height to stem diameter of B. ermanii showed the small value markedly compare to the trees inhabiting in the lower elevations. This suggests an adaptive trait for mountain environments including strong wind.

The rate of sprouting from stumps was $17-80 \%$ for $B$. ermanii compared to $33-61 \%$ for $B$. platyphylla var. japonica, and this was not significant $(P<0.05)$.

\section{Air and soil temperatures}

The mean annual temperatures for each elevation
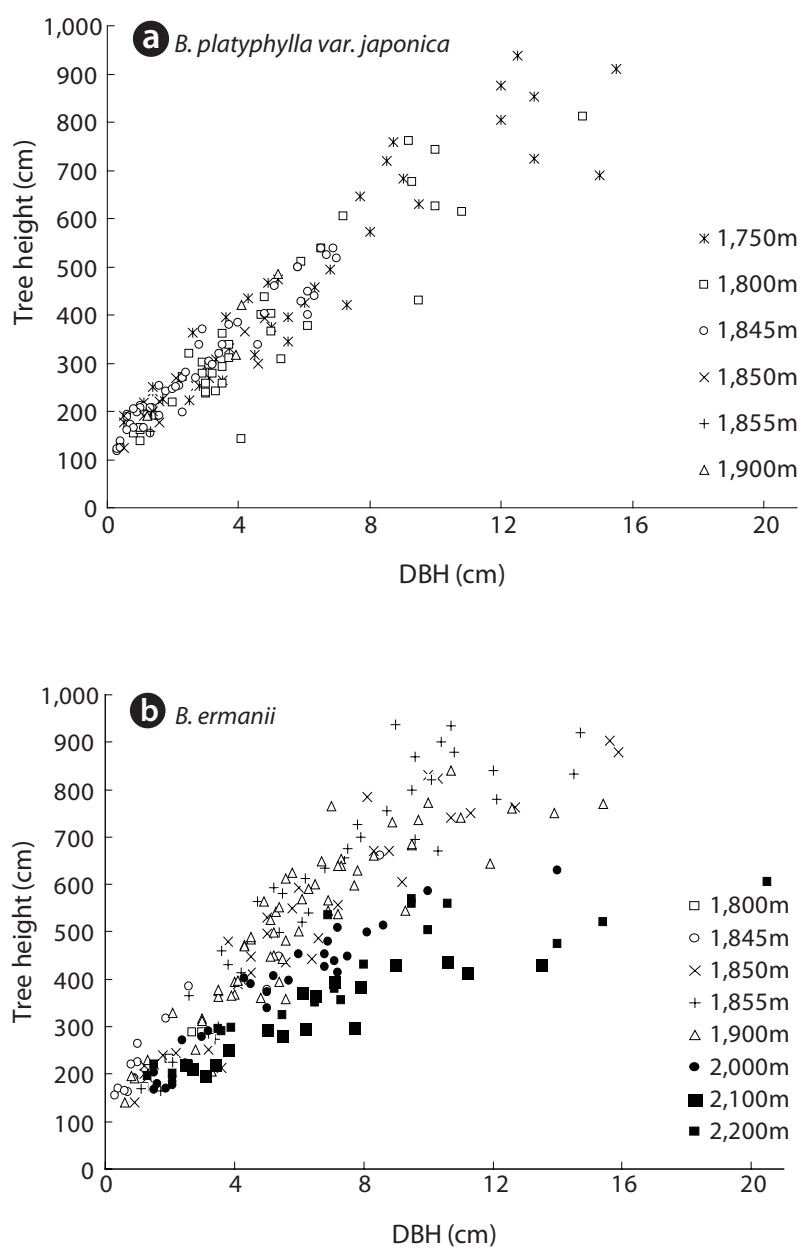

Fig. 4. Relationship between tree height and diameter at breast height (DBH) of Betula ermanii (a) and Betula platyphylla var. japonica at different elevations.

were $5.0^{\circ} \mathrm{C}$ in $1,700 \mathrm{~m}, 4.0^{\circ} \mathrm{C}$ in $1,850 \mathrm{~m}, 3.1^{\circ} \mathrm{C}$ in $1,950 \mathrm{~m}$ and $1.5^{\circ} \mathrm{C}$ in $2,200 \mathrm{~m}$. The annual average, average highest and average lowest temperatures, as well as the soil temperatures at a depth of $10 \mathrm{~cm}$ in growing season from April to September over the elevation range 1,700 to 2,200 $\mathrm{m}$ are shown in Fig. 5. Mean air temperature declined linearly with elevation at a lapse rate of $0.7^{\circ} \mathrm{C}$ per $100 \mathrm{~m}$. In 1996 , the mean air temperature during growing season at $1,850 \mathrm{~m}$ was $14.1^{\circ} \mathrm{C}$

The relationship between mean annual temperature at a given elevation on Mt. Neko and at the Sugadaira Montane Research Centre at Tsukuba University (SMRCT) at $1,320 \mathrm{~m}$ was estimated by the following equation:

$\mathrm{T}_{\mathrm{a}}=\left(\mathrm{T}_{\mathrm{b}}+1.65\right)-0.007(\mathrm{~A}-1320)$

Where, $\mathrm{T}_{\mathrm{a}}$ : mean annual temperature on Mt. Neko $\left({ }^{\circ} \mathrm{C}\right)$

$\mathrm{T}_{\mathrm{b}}$ : mean annual temperature measured at $\operatorname{SMRCT}\left({ }^{\circ} \mathrm{C}\right)$ A: elevation (m) 

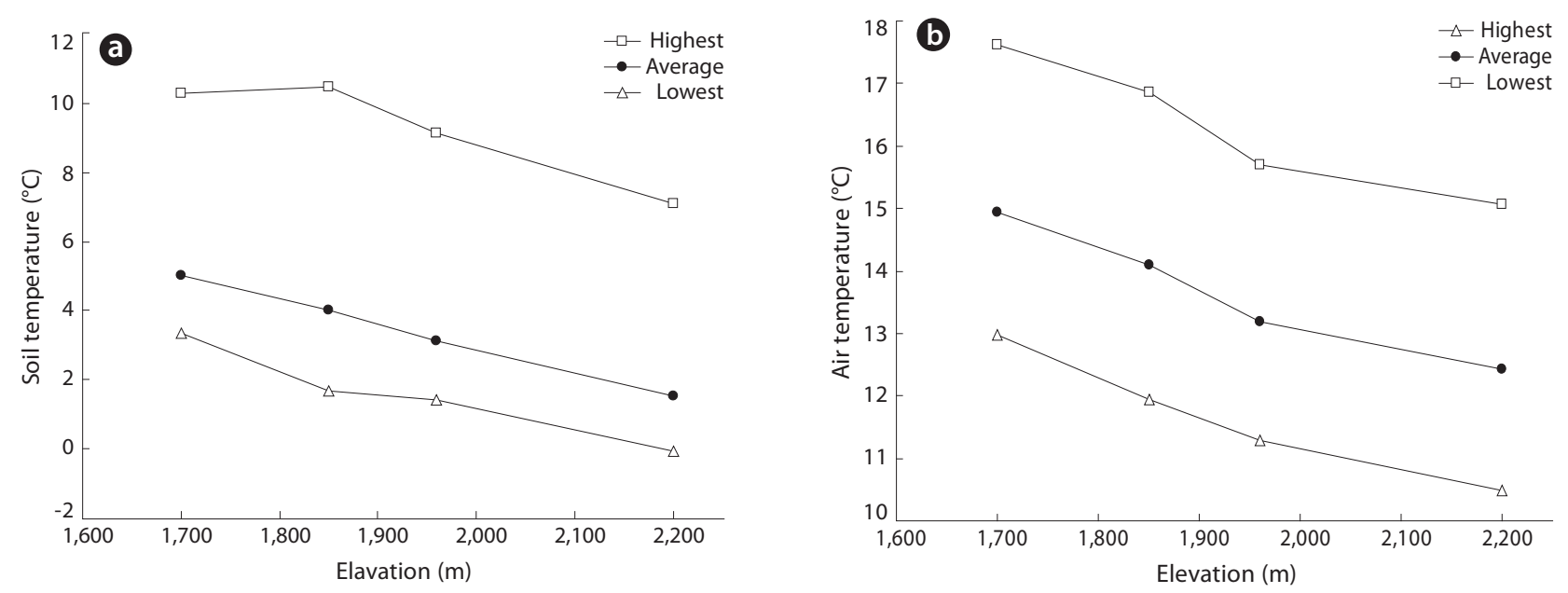

Fig. 5. Changes of temperatures in mean annual, average maximum and average minimum in air (a) and soil at $10 \mathrm{~cm}$ depth (b) from June to October, 1996 in the slope of Mt. Neko.

Given the strong correlation between the temperatures at both sites $(r=0.98)$ this equation was used to estimate the mean air temperature at any elevation using the measured values obtained at SMRCT. Using this method, the mean annual temperature at $1,850 \mathrm{~m}$ was estimated to be $4^{\circ} \mathrm{C}$ and $14.1^{\circ} \mathrm{C}$ during growing season between 1991 and 1996. These findings closely corroborated the values measured in 1996. Average annual minimum and maximum air temperatures also decreased with elevation, being $10^{\circ} \mathrm{C}$ and $20^{\circ} \mathrm{C}$, respectively.

Mean air temperature $\left(\mathrm{T}_{\mathrm{a}}\right)$ and mean soil temperature $\left(\mathrm{T}_{\mathrm{s}}\right)$ at depths of both $2 \mathrm{~cm}$ and $10 \mathrm{~cm}$ were strongly correlated at all elevations. For example, at 1,850 m, soil and air temperatures could be represented as follows:

$\mathrm{T}_{\mathrm{s}(10 \mathrm{~cm})}=0.88 \mathrm{~T}_{\mathrm{a}}+3.02 \quad r=0.97$

$\mathrm{T}_{\mathrm{s}(2 \mathrm{~cm})}=0.90 \mathrm{~T}_{\mathrm{a}}+4.48 \quad r=0.87$

Similar correlation coefficients were obtained for all elevations. We used equation (3) to elucidate which soil temperature conditions where important for seed germination. At 1,850 $\mathrm{m}$, the difference between the mean daily air and soil temperatures at a depth of $2 \mathrm{~cm}$ were $\geq 10^{\circ} \mathrm{C}$ for 25 days, $\geq 15^{\circ} \mathrm{C}$ for 17 days and $\geq 20^{\circ} \mathrm{C}$ for 5 days for during May to October 1996. The average daily difference in soil temperature was $15^{\circ} \mathrm{C}$ at $1,850 \mathrm{~m}$.

\section{Germination}

The germination rates of B. platyphylla var. japonica and B. ermanii under different temperature regimes are given in Table 2. For both species, the maximum germi- nation rate at a constant temperature was observed at $30^{\circ} \mathrm{C}$ when $74.0 \%$ and $42.5 \%$ of B. platyphylla var. japoni$c a$ and B. ermanii germinated, respectively. At a constant temperature of $10^{\circ} \mathrm{C}$, only $0.5 \%$ of the B. platyphylla var. japonica germinated. No seeds of $B$. ermanii germinated below $20^{\circ} \mathrm{C}$. Indeed, under the same temperature conditions, germination B. platyphylla var. japonica was consistently higher than that observed in B. ermanii. Under the condition of alternating temperature, $77-89 \%$ of $B$. platyphylla var. japonica germinated. For B. ermanii, $82 \%$ of seedlings germinated under the $10-30^{\circ} \mathrm{C}$ regime. The germination rates after cold stratification at $4^{\circ} \mathrm{C}$ are shown in Table 3. Stratification greatly promoted the germination in both species, but was particularly effective for B. ermanii in which $66 \%$ and $43 \%$ of seedlings germinated under constant temperatures of $15^{\circ} \mathrm{C}$ and $20^{\circ} \mathrm{C}$, respectively.

\section{Seedling growth}

The dry weight of the B. ermanii and B. platyphylla var. japonica seedlings grown under different temperature conditions is given in Fig. 6; both species showed enhanced growth at higher temperatures. The relative growth rates (RGRs) at $14.1^{\circ} \mathrm{C}$ (the mean annual temperature at $1,850 \mathrm{~m}$ during the growing season) were $0.031 \mathrm{~g} /$ day for B. platyphylla var. japonica and $0.029 \mathrm{~g} /$ day for $B$. ermanii, respectively, and these values did not differ significantly. The percentage survival of both species at constant temperatures of $10^{\circ} \mathrm{C}$ and $14^{\circ} \mathrm{C}$ and under natural conditions at different elevations on Mt. Neko are shown in Table $4 \mathrm{a}$ and $4 \mathrm{~b}$. The percentage survival of B. platyphylla var. japonica and B. ermanii seedlings was $50 \%$ 
Table 2. Germination rates (\%) of Betula platyphylla var. japonica and Betula ermanii with standard errors

\begin{tabular}{ccc}
\hline & \multicolumn{2}{c}{ Germination rate and standard error } \\
\cline { 2 - 3 } Temperature $\left({ }^{\circ} \mathrm{C}\right)$ & B. platyphylla var. japonica & B. ermanii \\
\hline 10 & $0.5 \pm 0.2$ & $0.0 \pm 0.0$ \\
15 & $7.5 \pm 1.8$ & $0.0 \pm 0.0$ \\
20 & $23.0 \pm 1.7$ & $0.0 \pm 0.0$ \\
25 & $64.0 \pm 2.4$ & $13.0 \pm 0.9$ \\
30 & $74.0 \pm 2.1$ & $42.5 \pm 2.0$ \\
$10 / 20^{*}$ & $77.0 \pm 1.2$ & $29.0 \pm 4.5$ \\
$15 / 25^{*}$ & $89.0 \pm 1.5$ & $35.0 \pm 6.2$ \\
$10 / 30^{*}$ & $89.0 \pm 0.9$ & $82.0 \pm 5.5$
\end{tabular}

*Low temperature, 16 hours; High temperature, 8 hours.

Table 3. Germination rates (\%) of Betula platyphylla var. japonica and Betula ermanii with standard errors under stratification of $4^{\circ} \mathrm{C}$ for 134 days

\begin{tabular}{ccc}
\hline & \multicolumn{2}{c}{ Germination rate and standard error } \\
\cline { 2 - 3 } Temperature $\left({ }^{\circ} \mathrm{C}\right)$ & B. platyphylla var. japonica & B. ermanii \\
\hline 10 & $0.0 \pm 0.0$ & $6.0 \pm 0.0$ \\
15 & $56.0 \pm 5.2$ & $43.0 \pm 8.0 \pm 7.8$ \\
20 & $79.3 \pm 2.8$ & $81.0 \pm 4.1$ \\
25 & $92.7 \pm 1.0$ & $80.0 \pm 1.7$ \\
30 & $92.7 \pm 1.2$ & $88.0 \pm 1.1$ \\
$10 / 20^{*}$ & $90.0 \pm 0.8$ & $88.0 \pm 2.7$ \\
$15 / 25^{*}$ & $88.7 \pm 1.4$ & $92.0 \pm 0.5$
\end{tabular}

*Low temperature, 16 hours; High temperature, 8 hours.
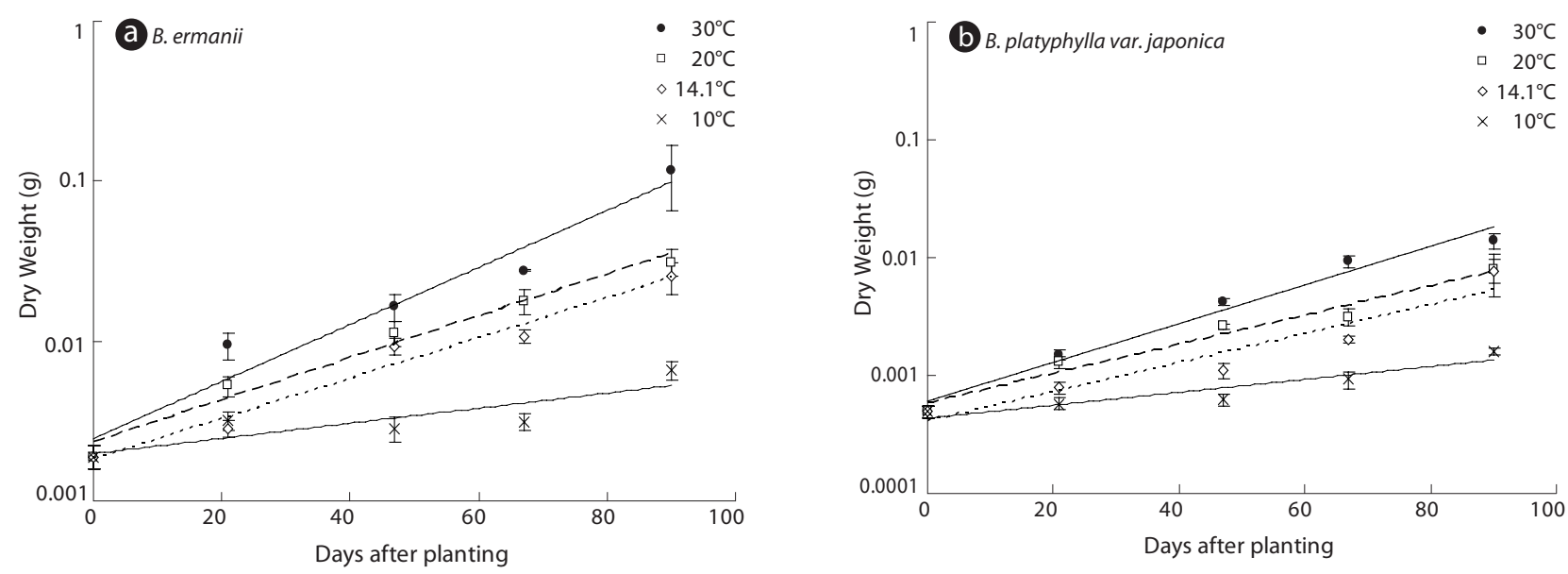

Fig. 6. Growth of seedlings of Betula ermanii (a) and Betula platyphyllavar. japonica (b) incubated in a growth chamber at $10,14,20$ and $30^{\circ} \mathrm{C}$. Vertical bars are standard error. 
Table 4a. Survival rate (\%) of seedlings of Betula platyphylla var. japonica and Betula ermanii at temperatures of $10^{\circ} \mathrm{C}$ and $14^{\circ} \mathrm{C}$ in the labotratory

\begin{tabular}{|c|c|c|c|c|}
\hline \multirow[b]{4}{*}{ Days after planting } & \multicolumn{4}{|c|}{ Survival rate (\%) } \\
\hline & \multirow[t]{2}{*}{$\begin{array}{c}\text { B. platyphylla } \\
\text { var. japonica }\end{array}$} & & \multicolumn{2}{|c|}{ B. ermanii } \\
\hline & & \multicolumn{3}{|c|}{ Temperature $\left({ }^{\circ} \mathrm{C}\right)$} \\
\hline & 10 & 14 & 10 & 14 \\
\hline 0 & 100.0 & 100.0 & 100.0 & 100.0 \\
\hline 21 & 66.7 & 100.0 & 100.0 & 100.0 \\
\hline 47 & 16.7 & 58.3 & 75.0 & 100.0 \\
\hline 67 & 33.3 & 50.0 & 100.0 & 75.0 \\
\hline 90 & 50.0 & 83.3 & 100.0 & 100.0 \\
\hline
\end{tabular}

Table 4b. Survival rate (\%) of seedlings of Betula platyphylla var. japonica and Betula ermanii on Mt. Neko

\begin{tabular}{|c|c|c|c|c|}
\hline & \multicolumn{4}{|c|}{ Survival rate $(\%)$} \\
\hline & \multicolumn{4}{|c|}{ Elevation (m) } \\
\hline & \multicolumn{4}{|c|}{ B. platyphylla var. japonica } \\
\hline Days after planting & 1600 & 1850 & 2050 & 2200 \\
\hline 0 & 100.0 & 100.0 & 100.0 & 100.0 \\
\hline 52 & 10.0 & 10.0 & 30.0 & 20.0 \\
\hline \multirow[t]{2}{*}{92} & 0.0 & 10.0 & 10.0 & 20.0 \\
\hline & \multicolumn{4}{|c|}{ B. ermanii } \\
\hline Days after planting & 1600 & 1850 & 2050 & 2200 \\
\hline 0 & 100.0 & 100.0 & 100.0 & 100.0 \\
\hline 52 & 60.0 & 80.0 & 90.0 & 70.0 \\
\hline 92 & 40.0 & 80.0 & 90.0 & 60.0 \\
\hline
\end{tabular}

and $100 \%$ at $10^{\circ} \mathrm{C}$ after 90 days of planting. Conversely, at $14^{\circ} \mathrm{C}$, percentage survival among seedlings was $80 \%$ in B. platyphylla var. japonica and $100 \%$ in B. ermanii (Table $4 \mathrm{a}$ ). Under a constant temperature of $10^{\circ} \mathrm{C}, 75 \%$ of the $B$. ermanii seedlings were still healthy by 47 days after planting. Under natural condition, the survival rates of seedlings of B. platyphylla var. japonica were $10 \%$ at both $1,850 \mathrm{~m}$ and $2,050 \mathrm{~m}$ and of $B$. ermanii seedlings were $80 \%$ and $90 \%$ at the same elevations after 92 days of planting (Table 4b).

\section{Leaf phenology}

The stage of leaf unfolding in B. platyphylla var. japonica and B. ermanii, and the modified Kira's WI are shown in Fig. 7. Leaf expansion began (stage L2) at $58^{\circ} \mathrm{C}$ day in B. platyphylla compared to $169^{\circ} \mathrm{C}$ day in B. ermanii. B. platyphylla var. japonica required $240^{\circ} \mathrm{C}$ day for full leaf expansion (stage L5) compared to $330^{\circ} \mathrm{C}$ day for B. ermanii.

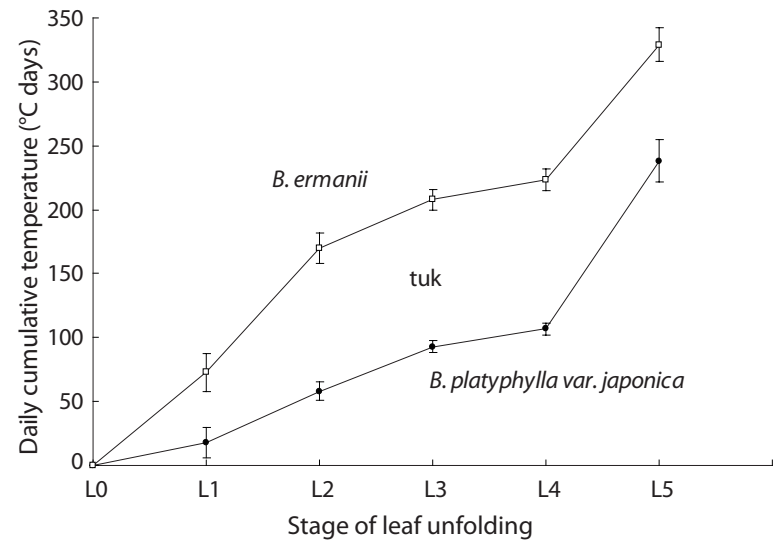

Fig. 7. Leaf unfolding stages related to the modified Kira's warmth index for Betula ermanii and Betula platyphylla var. japonica. Vertical bars are standard error.

B. ermanii thus required higher daily cumulative temperatures for the initiation of leaf unfolding compared to B. platyphylla var. japonica, which meant that B. platyphylla var. japonica unfolded its leaves earlier than $B$. 
Table 5a. Dates of each leaf unfolding stage with standard errors at 1,850 m on Mt. Neko, 1997

\begin{tabular}{ccc}
\hline Stage & $\begin{array}{c}\text { Betula platyphylla var. } \\
\text { japonica }\end{array}$ & Betula ermanii \\
L1 & 29 Apr \pm 3.5 days & 21-May \pm 2.1 days \\
L2 & 18 May \pm 2.0 days & 05-Jun \pm 0.9 days \\
L3 & 27 May \pm 0.6 days & 12-Jun \pm 0.4 days \\
L4 & 29 May \pm 2.2 days & 13-Jun \pm 1.5 days \\
L5 & 15 Jun \pm 3.3 days & 26-Jun \pm 3.2 days \\
\hline
\end{tabular}

Table 5b. Dates of late spring frosts and associated minimum air temperature at 1,850 m on Mt. Neko, 1997

\begin{tabular}{cc}
\hline Date of latest frost & Minimum air temperature $\left({ }^{\circ} \mathbf{C}\right)$ \\
\hline 05 May & -2 \\
06 May & -13 \\
07 May & -4.1 \\
09 May & -2.5 \\
10 May & -1.7 \\
12 May & -0.3 \\
13 May & -1.6 \\
15 May & -1.3 \\
\hline
\end{tabular}

ermanii (Watanabe 1996). However, the WI of L4 stage needed $106^{\circ} \mathrm{C}$ day in $B$. ermanii, whereas $131^{\circ} \mathrm{C}$ day $B$. platyphylla var. japonica. Leaves of $B$. ermanii thus expanded comparatively quickly once unfolding started and attained full development. Compared to B. platyphylla var. japonica, it took 15 days longer for B. ermanii to pass from the L1 to the L2 stage, but 8 days less to pass from the L4 to the L5 stage (Kojima et al. 2003, Kato and Hayashi 2008).

The dates when each leaf stage was reached at an altitude of 1,850 $\mathrm{m}$ are given in Table $5 \mathrm{a}$. The L1 stage when the bud swells and the terminal end splits to expose the green tissues inside was reached on 29 April in B. platyphylla var. japonica and on 21 May in B. ermanii, a difference of more than 20 days. The L2 stage was reached on 18 May in B. platyphylla var. japonica and on 5 June in B. ermanii and the final stage (L5) was attained on 15 June in B. platyphylla var. japonica and on 26 June in $B$. ermanii.

Table $5 \mathrm{~b}$ shows the dates of late spring frosts at $1,850 \mathrm{~m}$ and the minimum air temperatures on those days. The last frost occurred on 15 May 1997, after the leaves of $B$. platyphylla var. japonica had begun to unfold. By this date B. platyphylla var. japonica was between the $\mathrm{L} 1$ and L2 stages, whereas B. ermanii was still in the winter bud stage (L0), implying that they escaped the potential damage associated with late spring frost.

The biological characteristics of both species are summarised in Table 6. Briefly, B. ermanii germinates and/ or grows at temperatures lower than those preferred by B. platyphylla var. japonica. Cold stratification for seeds and temperature alternation from 10 to $30^{\circ} \mathrm{C}$ increased germination rates in both species. Non-stratified B. ermanii seeds did not germinate below $20^{\circ} \mathrm{C}$, while germination occurred in B. platyphylla var. japonica at temperatures ranging from 10 to $30^{\circ} \mathrm{C}$. The seedlings of both species grew best at $30^{\circ} \mathrm{C}$. Below $14.1^{\circ} \mathrm{C}$ the survival rate of B. ermanii was higher than that of B. platyphylla var. japonica under both experimental and field conditions. Leaf unfolding in B. platyphylla var. japonica commenced after $60^{\circ} \mathrm{C}$ day of modified Kira's WI before the equivalent $160^{\circ} \mathrm{C}$ day required for B. ermanii (Fig. 7). Finally, it was noted that the ratio of tree height versus DBH in B. ermanii varied considerably more than in $B$. platyphylla var. japonica with increasing elevation.

\section{DISCUSSION}

There are two possible hypotheses for the transition from B. platyphylla var. japonica to B. ermanii on Mt. Neko. The first hypothesis is that any discontinuous environmental conditions, including temperature in particular, exist along the altitudinal gradient. However, no such discontinuity was observed in either air or soil temperature gradients, or in mean air temperatures which decreased linearly with increasing elevation (Fig. 5). Thus, the first hypothesis was not supported by observed environmental conditions.

The second hypothesis was that these species respond differently to the same environmental cues due to their different biological characteristics such as timing of leaf unfolding, seed germination, frost avoidance and tolerance to heavy wind (Table 6) (Maruyama 1978, Linkosalo et al. 2000, Arora and Boer 2005). For example, leaf unfolding was initiated at a modified Kira's WI of $160^{\circ} \mathrm{C}$ day in B. ermanii whereas leaf unfolding in B. platyphylla var. japonica occurred at $60^{\circ} \mathrm{C}$ day at the same elevation. In other words, B. platyphylla var. japonica began leaf unfolding earlier than B. ermanii at the same elevation. At 
sites above 1,850 $\mathrm{m}$, where late-spring frosts were recorded from 5 May until 14 May 1997 and WI was $60^{\circ} \mathrm{C}$ day, the leaves of B platyphylla var. japonica were observed to have unfolded whereas the leaves in B. ermanii were still in winter buds. This meant that B. ermanii could avoid damage due to late frost while B. platyphylla var. japoni$c a$ could not. No frosts occurred in the lower zone at this critical point in the growing season, which determines leaf unfolding in B. platyphylla var. japonica. Thus, the second hypothesis appears to offer a more likely reason for the transition between B. platyphylla var. japonica and B. ermanii at $1,850 \mathrm{~m}$ on Mt. Neko.

The principal difference in the vertical distribution of these two species was the timing of leaf unfolding and how this related to the occurrence of late spring frosts. According to field observations, frost damage to the young leaves of B. platyphylla var. japonica appeared to arrest leaf growth. However, during the same period, the leaves of B. ermanii were not damaged because the buds remained in their winter state until the risk of frost had passed.

Kojima et al. (2003) exposed buds of $F$. crenata in the winter bud stage (stage L0) and in early stage of leaf unfolding (stages L2-L3) to artificial frost. While the winter buds were not damaged by the frost and began unfolding normally afterwards, the L2-L3-stage buds did not unfold. This is likely to be the main reason why B. platyphylla var. japonica cannot become established above 1,850 m. On
5 May 1997, ice crystals were observed to have formed on the ends of upper branches of $B$. ermanii growing above $1,900 \mathrm{~m}$. The frost did not damage the leaves of B. ermanii because they were protected by their winter buds, however, the unfolding leaves (stage L3) of B. platyphylla var. japonica were observed to be damaged.

The seeds of both species were produced in September (Table 6). Only a few seeds of B. ermanii germinate in autumn of the current year because they require moist stratification. These seeds contribute to the buried seed population and normally germinate in the following spring. On the other hand, the seeds of B. platyphylla var. japonica germinate soon after production, as they do not require stratification. The resulting seedlings cannot endure the cold winter conditions at high elevations and therefore cannot become established; in the areas where there is no late frost, such germination behaviour is considered advantageous. The seedlings of $B$. ermanii must be more tolerable for cold environment than that of B. platyphulla var. japonica because the seeds of former species are heavier than the latter species.

The thick, stunted growth form of B. ermanii trees growing near the summit of Mt. Neko, is well adapted to the strong winds and snow conditions (Okitsu and Satomi 1989). This morphological adaptation of trees to wind, which has been reported in several tree species (Larson 1965, Neel and Harris 1971, Lawton 1982), enables B. ermanii to survive on mountain summits (Ohsawa 1984)

Table 6. Biological characteristics of Betula platyphylla var. japonica and Betula ermanii

\begin{tabular}{|c|c|c|}
\hline & B. platyphylla var. japonica & B. ermanii \\
\hline Distribution (elevation, m) & $1,750-1,850$ & $1,850-2,000$ \\
\hline Growth plasticity of tree & Not plasticized & Plasticized \\
\hline Temperature maximum germination occurred $\left({ }^{\circ} \mathrm{C}\right)$ & 30 & 30 \\
\hline Temperature alternation maximum germination occurred $\left({ }^{\circ} \mathrm{C}\right)$ & Alternate $10 / 30^{\circ} \mathrm{C}$ & Alternate $10 / 30^{\circ} \mathrm{C}$ \\
\hline Germination rate cold stratification applied & Promoted & Promoted \\
\hline Leaf unfolding time (elevation of $1,320 \mathrm{~m}$ ) & Beginning of May & Beginning of June \\
\hline Leaf unfolding speed & Slow & Quick \\
\hline Time attained maximum leaf size & May & June \\
\hline Time seed matured & September & September \\
\hline Seed dispersal type & Wind & Wind \\
\hline Air dried seed weight (g) & 0.0906 & 0.5940 \\
\hline Number of seed in one bunch & 817 & 383 \\
\hline Ratio of wing weight / intact seed weight (\%) & 16.5 & 8.1 \\
\hline Daily cumulative temperature for leaf unfolding $\left({ }^{\circ} \mathrm{C}\right.$ day $)$ & 238 & 329 \\
\hline No. of day of leaf unfolding (days) & 43.4 & 36.9 \\
\hline No. of day of surplus production (days) & 115.8 & 119.6 \\
\hline No. of day of leaf fall & 64.8 & 28.9 \\
\hline
\end{tabular}


and is an important factor affecting the establishment of the B. ermanii zone in Hokkaido (Okitsu 1999). The absence of this form in B. platyphylla var. japonica further limits the success of this species in high mountain environments.

Taken together, these biological characteristics of $B$. platyphylla var. japonica and B. ermanii affect the transition between the two species at an elevation of 1,850 $\mathrm{m}$ on Mt. Neko, where the mean annual air temperature is $4^{\circ} \mathrm{C}$. These same environmental factors, which favour the segregation of B. platyphylla japonica and B. ermanii at high elevations are also considered to affect the geographic distribution of these two species. Indeed, the $4^{\circ} \mathrm{C}$ mean annual isotherm passes between Hokkaido and Sakhalin and coincides with the boundaries of their ranges (Kojima 1994). The distribution of B. ermanii on Hokkaido is primarily that area where the mean annual air temperature is 4 .

On a large geographic scale, temperature is considered to be the primary environmental factor determining the vertical and horizontal distributions of these species. On a more local scale, the interrelationship between the biological and ecological characteristics of plants and their physical environments affect species segregation within a stand.

\section{LITERATURE CITED}

Arora VK, Boer GJ. 2005. A parameterization of leaf phenology for the terrestrial ecosystem component of climate models. Grobal Change Biol 11: 39-59

Chuine I, Beaubien EG. 2001. Phenology is a major determinant of tree species range. Ecol Lett 4: 500-510.

Imanishi K. 1949. Theoretical consideration of bio-community. Mainichi Shinbunn-sha, Tokyo. (in Japanese)

Kato J, Hayashi I. 2008. Phenological studies of deciduous trees in the cool temperate region of Japan. J Ecol Field Biol 31: 193-200.

Kikuzawa K. 1983. Leaf survival of woody plants in deciduous broad-leaved forests: 1. Tall trees. Can J Bot 61: 2133-2139.

Kojima H, Mariko S, Nakamura T, Hayashi I. 2003. Bud burst process and late-frost experiments on Fagus crenata and Quercus mongolica ssp. crispula. Veg Sci 20: 55-64.

Kojima S. 1994. Vegetation and environment of Betula ermanii forest on the Kamchatka Peninsula. Jpn J Ecol 44: 4959. (in Japanese)
Kudo G. 1995. Altitudinal effects on leaf traits and shoot growth of Betula platyphylla var. japonica. Can J For Res 25: 1881-1885.

Larson PR. 1965. Stem form of young Larix as influenced by wind and pruning. For Sci 11: 412-424.

Lawton RO. 1982. Wind stress and elfin stature in a montane rain forest tree: an adaptive explanation. Am J Bot 69: 1224-1230.

Linkosalo T, Carter TR, Häkkinen R, Hari P. 2000. Predicting spring phenology and frost damage risk of Betula spp. under climatic warming: a comparison of two models. Tree Physiol 20: 1175-1182.

Maruyama K. 1978. Shoot elongation characteristics and phenological behaviour of forest trees in natural beech forest. Ecological studies on natural beech forest (32). Bull Niigata Univ For 11: 1-30. (in Japanese with English summary)

Neel PL, Harris RW. 1971. Motion-induced inhibition of elongation and induction of dormancy in Liquidamabar. Science 173: 58-59.

Numata M. 1987. Papers of theoretical consideration on Plant Ecology. Tokai-daigaku Shuppann, Tokyo. (in Japanese)

Ohsawa M. 1984. Differentiation of vegetation zones and species strategies in the sub-alpine region of Mt. Fuji. Vegetatio 57: 15-52.

Okitsu S.1999. Distribution of the forest of the boreal zone of north eastern Asia and conditions for the establishment of the forest boundary. Vegetation Science 16:83-97. (in Japanese with English summary)

Okitsu S, Satomi I. 1989. Relationship between tree height and diameter of Betula ermanii growing at the forest limit on the high mountains of central Japan. J Phytogeogr Taxon 37: 149-153. (in Japanese with English summary)

Raulier F, Bernier PY. 2000. Predicting the date of leaf emergence for sugar maple across its native range. Can J For Res 30: 1429-1435.

Takahashi K. 1962. Studies on vertical distribution of the forest in middle Honshu. Bull Gov For Exp Stat 142: 1-171. (in Japanese)

Tanouchi H, Hayashi I. 1981. Analytical study on the vegetation of Sugadaira, Central Japan. Hikobia Suppl 1: 265276. (in Japanese)

Watanabe R. 1996. Individual and annual variation on the phenology of B. ermanii. Bull Inst Nat Educ Shiga Heights Shinshu Univ 33: 15-26. (in Japanese) 